\title{
Post-transplant lymphoproliferative disease
}

\author{
Vikas R. Dharnidharka • Carlos E. Araya
}

Received: 15 May 2007 /Revised: 22 June 2007 / Accepted: 12 July 2007 / Published online: 19 September 2007

(C) IPNA 2007

\begin{abstract}
Post-transplant lymphoproliferative disease (PTLD) emerged in the mid-1990s as a major graft- and life-threatening complication of pediatric kidney transplantation. This condition, usually involving uncontrolled B lymphocyte proliferation, straddles the border between infection and malignancy, since Epstein-Barr virus (EBV) is intimately associated with the pathogenesis. PTLD is seen more in younger children (more likely to be EBV seronegative), Caucasian race, and in association with the more potent immunosuppression drugs. The clinical presentation typically involves multiple enlarged lymph nodes but varies based on localization of the lymphadenopathy. The diagnosis is based primarily on histopathological features. Treatment strategies include reduction of immunosuppression, use of anti-B cell antibodies, infusion of EBV-specific cytotoxic $\mathrm{T}$ lymphocytes, and chemotherapy. Many different strategies have been tried to prevent PTLD, ranging from serial EBV viral load monitoring and pre-emptive immunosuppression reduction to anti-viral prophylaxis. None of the major treatment or prevention strategies has been subject to randomized clinical trials, so their relative efficacy is still unknown. PTLD remains a risk factor for graft loss, though re-transplants have not, to date, been associated with repeat PTLD.
\end{abstract}

Keywords Post-transplant lymphoproliferative disease . Pediatrics $\cdot$ Kidney

\section{Abbreviations \\ PTLD Post-transplant lymphoproliferative disease EBV Epstein-Barr virus}

V. R. Dharnidharka $(\square) \cdot$ C. E. Araya

Division of Pediatric Nephrology,

University of Florida College of Medicine,

PO Box 100296,

1600 SW Archer Road,

Gainesville, FL 32610-0296, USA

e-mail: vikasmd@peds.ufl.edu
CMV Cytomegalovirus
PCR Polymerase chain reaction
CsA Cyclosporine A
CTL Cytotoxic T lymphocytes

\section{Introduction}

PTLD is a major graft- and life-threatening complication of solid organ transplantation. This condition is best defined as an uncontrolled proliferation of lymphocytes within the context of post-transplant immunosuppression. In children, most of the proliferating lymphocytes are of B cell lineage and are driven by Epstein-Barr virus infection [1]. Sometimes, the proliferations are reversible by reduction of immunosuppression, thus distinguishing PTLD from true malignancy. At other times the severe forms of PTLD are indistinguishable from frank lymphoma. Previously thought to be rare in children receiving kidney transplants, the cumulative incidence of PTLD in this population kept rising through the mid-1990s and early part of this decade [2]. The emergence of Epstein-Barr virus (EBV)-PTLD was part of a sequence of emerging viral infections in transplantation, starting with cytomegalovirus (CMV), followed by EBV and later followed by BK virus. This teaching article focuses on PTLD after pediatric kidney transplantation. Several excellent reviews have covered PTLD across different organ and tissue transplants [1, 3-8].

\section{Pathophysiology}

The pathophysiology of PTLD has been described $[1,4,8]$. EBV is a DNA virus of the gamma herpes family. Most immunocompetent individuals acquire subclinical infection at some point prior to adulthood. The virus establishes a 
long-lived latency in reticuloendothelial cells, similar to another herpes virus cytomegalovirus. B lymphocytes are an important reservoir for EBV. Left unchecked, the virus will insert its own genome into the B cell and induce uncontrolled B cell proliferation. However, immunocompetent individuals can keep the infected B cells in check through EBV-specific CD8+ cytotoxic T lymphocytes (CTLs). When transplant recipients receive immunosuppression to prevent rejection, an important consequence of such non-specific immunosuppression is the inhibition of the EBV-specific CTLs. Thus, in this setting, EBV-infected B cells may proliferate unchecked. This proliferation is particularly marked when the transplant recipient is EBV seronaive and acquires a primary infection when immunosuppressed.

\section{Epidemiology of PTLD}

The highest risk of PTLD is in the EBV seronegative recipient who receives a kidney allograft from an EBV seropositive donor. Multiple studies have shown that the risk of PTLD in such cases is increased threefold to 24-fold [5, 913]. CMV co-infection can further add to the risk [13].

PTLD rates vary with the organ transplanted. Thoracic (heart, lung or combined) and intestinal transplants have the highest rates of PTLD, typically in the $5-10 \%$ range $[5$, 14]. Pediatric kidney transplants were previously associated with PTLD rates of $<1 \%$, but these rates have climbed and are now in the $2-4 \%$ range at $3-5$ years after transplantation $[2,14,15]$. Prospective studies have mirrored this trend. The IN01 study was the first National Institutes of Health (NIH)-sponsored multi-centered clinical trial in pediatric kidney transplantation in the USA, conducted between 1994 and 1999. In that study, the PTLD rates were $3.4 \%$ in the OKT3 induction arm and $2.1 \%$ in the cyclosporine $\mathrm{A}(\mathrm{CsA})$ induction arm, with a mean follow-up time of 44 months for all study participants [16]. In contrast, the next NIH-sponsored study, the SW01 trial of steroid withdrawal in pediatric kidney transplant recipients conducted between 1999 and 2004, had an overall PTLD rate of $6 \%$ in both arms, leading to early termination of that study [17]. In comparison to kidney allografts, PTLD rates are $8 \%$ by 5 years after transplantation in the Pediatric Heart Transplant Study [5]. The most recent national data from pediatric liver transplants, from the United Network for Organ Sharing (UNOS) and SPLIT liver transplant registries, indicate a $2.4 \%$ cumulative incidence of PTLD [14].

PTLD was very rare in the days of two-drug immunosuppression after transplantation using azathioprine and orally administered steroids. Reports of PTLD started increasing after the introduction of cyclosporine A and then other newer immunosuppressive agents, such as induction antibodies. In general, the higher the "total intensity" of immunosuppression, the higher the risk for PTLD. Individual drugs may or may not increase the risk. For most of the typically used drugs, small single center studies cannot accumulate large enough samples to delineate a higher risk fully. In contrast, large registry databases, especially in the United States of America, can evaluate large samples but do not have EBV information, and the quality and completeness of the data are inferior to single center information. Thus, both types of studies involve a trade-off. As such, CsA, OKT3, rabbit anti-thymocyte globulin, basiliximab and daclizumab have all been associated with higher PTLD risk in at least one study [13, 18, 19], though, for each drug, there are also studies documenting no higher risk [20-22]. Cyclosporine was compared to tacrolimus by the Cochrane Review Group, and no significant differences in relative risk for PTLD were found in this metaanalysis of 30 different prospective trials [23]. Mycophenolate mofetil has not been associated with higher PTLD risk to date [2] but has been associated with higher risk for CMV and BK virus infections [24]. Sirolimus has shown some anti-EBV effects in vitro $[25,26]$, and a large registry study suggested lower incidence of malignancy with early use of mammalian target of rapamycin (mTOR) inhibitor [27].

\section{Pathology}

PTLD lesions can range from mild lymphoid hyperplasia to frank lymphoma, with several grades in between [28]. Most lesions are either polymorphic or monomorphic. Additional classifications based on clonality are available, dividing lesions into polyclonal and monoclonal, the latter considered more severe. EBV staining via Epstein Barr early RNA (EBER) and latent membrane protein (LMP) help us to determine if the tumor cells contain EBV. CD20 staining of the lymphocytes helps us to decide if anti-CD20 antibody therapy will be useful.

\section{Clinical features}

PTLD can present in a variety of ways, so a high index of suspicion must be maintained at all times [29]. The most common presentation is with lymph node enlargement, either in easily visible sites (such as cervical) or internal sites not immediately visible. In the latter case the symptoms are related to whichever internal structures have been compressed or impaired in function. Internal areas of presentation include the gut, bone marrow or central nervous system. Mass effects in these areas can present as vomiting/diarrhea, hematological cytopenias, or symptoms of brain tumors. The latter has the worst prognosis amongst all presentations. From North American Pediatric Renal 
Transplant Cooperative Study (NAPRTCS) data, lymph node involvement was the most common presentation, followed by abdomen, kidney allograft and central nervous system (Table 1). PTLD can involve the allograft itself and may rarely present as fever with no localizing features.

In children receiving kidney transplants, unlike in adults, most cases of PTLD occur in the first year after transplantation, when immunosuppression is most intense and chances of EBV primary infection are higher in the D+/Rmismatch. Early PTLD cases are almost always likely to be EBV-driven and of B cell lineage. The majority of late PTLD cases are also EBV driven and of B cell lineage, but the proportion of non-EBV or T cell PTLD is higher in late PTLDs. In addition to central nervous system involvement, other poor prognostic factors include monoclonal lesions, OKT3 use, elevated lactate dehydrogenase levels, and high tumor staging scores [30-34].

\section{Diagnosis}

The diagnosis is essentially based on histopathology, so a tissue specimen is usually needed. High peripheral blood EBV polymerase chain reaction (PCR) loads can support a diagnosis of EBV-PTLD but are not diagnostic themselves. Similarly, imaging techniques such as computed tomography (CT) or positron emission tomography (PET) [35] can help localize and stage the tumor but are not diagnostic. Oncologists can help with this staging. The differential diagnosis can include Bartonella infection [36], tuberculosis or reactive lymphadenopathy. EBV serology and monospot tests are not useful for diagnosis in the transplant setting.

\section{Treatment}

Most physicians will first reduce immunosuppression once PTLD has been diagnosed. However, there is no consensus on how to reduce immunosuppression or which drugs to target first. A commonly used approach is to reduce calcineurin inhibitors to half their dose or target level and discontinue

Table 1 Distribution of PTLD by anatomic location in pediatric kidney transplant recipients (data from NAPRTCS)

\begin{tabular}{ll}
\hline Site of involvement & Percentage of total \\
\hline Lymph node & 33 \\
Abdomen & 29 \\
Kidney allograft & 11 \\
Central nervous system & 11 \\
Other & 16 \\
\hline
\end{tabular}

anti-metabolite agents, while continuing oral steroid treatment [37]. This strategy is revaluated quickly, usually within 14 weeks, to determine if additional interventions are needed. Such revaluations should include clinical reassessment, EBV PCR response if initial load was high, and may also include follow-up imaging if needed. In cases of severe, disseminated disease, discontinuation of all immunosuppression, with the exception of steroids, has been tried. Anti-CD20 monoclonal antibody therapy (rituximab) is now widely accepted as the second line therapy in CD20-positive lesions $[38,39]$. Alpha interferon was used previously but has been replaced by rituximab. For more severe lesions or those that do not respond, chemotherapy with protocols used for nonHodgkin's lymphoma is employed, in conjunction with oncologists. Some protocols in common use will lower the dose of cyclophosphamide or combine low-dose cyclophosphamide and steroids with rituximab [40, 41]. Each of these strategies has a moderately high success rate in the appropriate situation, but no strategy is associated with $100 \%$ complete remission. There are no head-to-head randomized comparison trials to judge which therapy is more efficacious. Many centers will also use anti-viral agents concomitant with the above interventions. Typically, ganciclovir or valganciclovir are employed for this purpose, since these drugs are much more potent against EBV than acyclovir. The use of these drugs to treat or even prevent PTLD, though widespread, is considered controversial, since they affect only replicating viruses. In PTLD, most of the viral genome is in non-replicative phase, with EBV DNA copies being generated by replicating infected B cells.

\section{Other interventions}

Owing to the potential serious impact of graft loss or patient death that can occur with PTLD, many investigators have attempted immunosuppression minimization as part of a broader attempt to reduce the frequency of post-transplantation infections, including $\mathrm{BK}$ virus nephropathy, CMV infection and transplant pyelonephritis. Such minimization can involve any of several strategies, such as calcineurin inhibitor dose and target level reduction, avoidance of induction antibody, and avoidance of steroids or anti-metabolites [42, 43]. Some interventions could be implemented in "pre-emptive" fashion, as discussed below.

\section{Prevention}

Preventing PTLD is far more preferable to having to treat established disease. Primary prevention could be achieved by immunizing children against EBV prior to their becoming immunosuppressed. A vaccine developed against the gp350 
envelope glycoprotein is currently in phase I/II clinical trials in the UK [7].

Secondary prevention has been tried by several investigators, using either serial peripheral blood EBV PCR monitoring or immune function monitoring. When EBV loads are seen to rise, immunosuppression drug levels are reduced, or specific drugs are discontinued, to reduce the total intensity of immunosuppression. However, in children, not all rises in EBV viral load necessarily lead to PTLD. Some children may develop a chronic high load carrier state [44], so the efficacy of this strategy is still not fully defined. Another form of secondary prevention is the use of antiviral prophylaxis. The use of anti-viral agents has been discussed in the treatment section. As with treatment, use of anti-viral agents in prevention is also controversial, since the drugs do not prevent viremia from B cell proliferation. Both serial EBV monitoring and anti-viral prophylaxis have been associated with reduced incidence of PTLD, albeit in studies that were not randomized or prospective in nature.

\section{Outcomes}

Though many cases of PTLD respond to therapy, some do not. The most recent data from a large pediatric kidney transplant multi-center trial suggest that there is an improved prognosis compared to the prognosis before [17]. Nevertheless, data from NAPRTCS indicate that the risk of graft loss is clearly higher after PTLD has occurred. The optimum time to restart high-dose immunosuppression is not known. For organs such as heart and lung, graft dysfunction or rejection can be immediately life-threatening. If graft loss has occurred, PTLD has not been reported so far in the re-transplants [45].

Questions (Answers appear after the reference list)

(1) Which of the following interventions is not a preventive strategy for PTLD?

a. Reduction of immunosuppression

b. Anti-viral agent usage

c. Cyclophosphamide usage

d. Serial peripheral blood EBV PCR monitoring

(2) Which of the following interventions is not a treatment strategy for PTLD?

a. Reduction of immunosuppression

b. Anti-viral agent usage

c. Cyclophosphamide usage

d. Serial peripheral blood EBV PCR monitoring

(3) Which area of involvement with PTLD is associated with the worst prognosis?

a. Allograft involvement

b. Lymph node involvement c. Central nervous system involvement

d. Bone marrow involvement

(4) The following are risk factors for the development of PTLD except

a. Caucasian race

b. Recipient is seronegative for EBV at the time of transplant

c. Development of CMV disease

d. Use of mycophenolate mofetil (MMF)

(5) Which of the following factors has the strongest association with PTLD?
a. EBV infection
b. CMV infection
c. BK virus infection
d. Urinary tract infection

(6) In an immunocompetent host, the regulation and control of proliferation of the EBV-infected B cells occur primarily by means of
a. Plasma cells
b. Phagocytes (neutrophils, macrophages, dendritic cells)
c. Cytotoxic T cells
d. The complement system

(7) In pediatric kidney transplant recipients most cases of PTLD are observed

a. Within the first year of transplantation

b. Between the first and second year after transplantation

c. Five years after transplantation

d. Immediately after treatment for acute rejection

(8) All of the following statements are true, except

a. EBV viral loads may be elevated in the absence of clinical evidence of EBV disease or PTLD

b. EBV PCR is a useful screening test with high specificity for EBV disease and can replace histologic examination when the diagnosis of PTLD is considered

c. Immunosuppressive agents may result in false negative results of EBV serologic tests, even at the time of active EBV disease

d. Not every patient with PTLD will have elevated EBV viral loads

\section{References}

1. Green M, Webber S (2003) Posttransplantation lymphoproliferative disorders. Pediatr Clin North Am 50(6):1471-1491

2. Dharnidharka VR, Ho PL, Stablein DM, Harmon WE, Tejani AH (2002) Mycophenolate, tacrolimus and post-transplant lymphoproliferative disorder: a report of the North American Pediatric 
Renal Transplant Cooperative Study. Pediatr Transplant 6 (5):396-399

3. Bakker NA, van Imhoff GW, Verschuuren EA, van Son WJ (2007) Presentation and early detection of post-transplant lymphoproliferative disorder after solid organ transplantation. Transpl Int 20(3):207-218

4. LaCasce AS (2006) Post-transplant lymphoproliferative disorders. Oncologist 11(6):674-680

5. Webber SA, Naftel DC, Fricker FJ, Olesnevich P, Blume ED, Addonizio L, Kirklin JK, Canter CE, Pediatric Heart Transplant Study (2006) Lymphoproliferative disorders after paediatric heart transplantation: a multi-institutional study. Lancet 367 (9506):233-239

6. Lim WH, Russ GR, Coates PT (2006) Review of Epstein-Barr virus and post-transplant lymphoproliferative disorder post-solid organ transplantation. Nephrology (Carlton) 11(4):355-366

7. Shroff R, Rees L (2004) The post-transplant lymphoproliferative disorder - a literature review. Pediatr Nephrol 19(4):369-377

8. Gottschalk S, Rooney CM, Heslop HE (2005) Post-transplant lymphoproliferative disorders. Annu Rev Med 56:29-44

9. Allen UD, Farkas G, Hebert D, Weitzman S, Stephens D, Petric M, Tellier R, Ngan B, Fecteau A, West L, Wasfy S (2005) Risk factors for post-transplant lymphoproliferative disorder in pediatric patients: a case-control study. Pediatr Transplant 9(4):450-455

10. Cockfield SM, Preiksaitis JK, Jewell LD, Parfrey NA (1993) Posttransplant lymphoproliferative disorder in renal allograft recipients. Clinical experience and risk factor analysis in a single center. Transplantation 56(1):88-96

11. Gao SZ, Chaparro SV, Perlroth M, Montoya JG, Miller JL, DiMiceli S, Hastie T, Oyer PE, Schroeder J (2003) Posttransplantation lymphoproliferative disease in heart and heart-lung transplant recipients: 30 -year experience at Stanford University. J Heart Lung Transplant 22(5):505-514

12. Katz BZ, Pahl E, Crawford SE, Kostyk MC, Rodgers S, Seshadri R, Proytcheva M, Pophal S (2007) Case-control study of risk factors for the development of post-transplant lymphoproliferative disease in a pediatric heart transplant cohort. Pediatr Transplant 11(1):58-65

13. Walker RC, Marshall WF, Strickler JG, Wiesner RH, Velosa JA, Habermann TM, McGregor CG, Paya CV (1995) Pretransplantation assessment of the risk of lymphoproliferative disorder. Clin Infect Dis 20(5):1346-1353

14. Dharnidharka VR, Tejani AH, Ho PL, Harmon WE (2002) Posttransplant lymphoproliferative disorder in the United States: young Caucasian males are at highest risk. Am J Transplant 2 (10):993-998

15. Dharnidharka VR, Sullivan EK, Stablein DM, Tejani AH, Harmon WE (2001) Risk factors for posttransplant lymphoproliferative disorder (PTLD) in pediatric kidney transplantation: a report of the North American Pediatric Renal Transplant Cooperative Study (NAPRTCS). Transplantation 71(8):1065-1068

16. Benfield MR, Tejani A, Harmon WE, McDonald R, Stablein DM, McIntosh M, Rose S; The CCTPT Study Group (2005) A randomized multicenter trial of OKT3 mAbs induction compared with intravenous cyclosporine in pediatric renal transplantation. Pediatr Transplant 9(3):282-292

17. McDonald RA, McIntosh M, Stablein D, Grimm P, Wyatt R, Arar M, Lirenman D, Bridges N, Harmon WE (2005) Increased incidence of PTLD in pediatric renal transplant recipients enrolled in a randomized controlled trial of steroid withdrawal: a study of the CCTPT. Am J Transplant 5(Suppl 11):418 (abstract \#1028)

18. Bustami RT, Ojo AO, Wolfe RA, Merion RM, Bennett WM, McDiarmid SV, Leichtman AB, Held PJ, Port FK (2004) Immunosuppression and the risk of post-transplant malignancy among cadaveric first kidney transplant recipients. Am J Transplant 4 (1):87-93
19. Swinnen LJ, Costanzo-Nordin MR, Fisher SG, O'Sullivan EJ, Johnson MR, Heroux AL, Dizikes GJ, Pifarre R, Fisher RI (1990) Increased incidence of lymphoproliferative disorder after immunosuppression with the monoclonal antibody OKT3 in cardiactransplant recipients. N Engl J Med 323(25):1723-1728

20. Cherikh WS, Kauffman HM, McBride MA, Maghirang J, Swinnen LJ, Hanto DW (2003) Association of the type of induction immunosuppression with posttransplant lymphoproliferative disorder, graft survival, and patient survival after primary kidney transplantation. Transplantation 76(9):1289-1293

21. Opelz G, Dohler B (2004) Lymphomas after solid organ transplantation: a collaborative transplant study report. Am J Transplant 4 (2):222-230

22. Dharnidharka VR, Stevens G (2005) Risk for post-transplant lymphoproliferative disorder after polyclonal antibody induction in kidney transplantation. Pediatr Transplant 9:622-626

23. Webster AC, Woodroffe RC, Taylor RS, Chapman JR, Craig JC (2005) Tacrolimus versus ciclosporin as primary immunosuppression for kidney transplant recipients: meta-analysis and metaregression of randomised trial data. BMJ 331(7520):810

24. Ginevri F, De Santis R, Comoli P, Pastorino N, Rossi C, Botti G, Fontana I, Nocera A, Cardillo M, Ciardi MR, Locatelli F, Maccario R, Perfumo F, Azzi A (2003) Polyomavirus BK infection in pediatric kidney-allograft recipients: a single-center analysis of incidence, risk factors, and novel therapeutic approaches. Transplantation 75(8):1266-1270

25. Majewski M, Korecka M, Kossev P, Li S, Goldman J, Moore J, Silberstein LE, Nowell PC, Schuler W, Shaw LM, Wasik MA (2000) The immunosuppressive macrolide RAD inhibits growth of human Epstein-Barr virus-transformed B lymphocytes in vitro and in vivo: a potential approach to prevention and treatment of posttransplant lymphoproliferative disorders. Proc Natl Acad Sci USA 97(8):4285-4290

26. Nepomuceno RR, Balatoni CE, Natkunam Y, Snow AL, Krams SM, Martinez OM (2003) Rapamycin inhibits the interleukin 10 signal transduction pathway and the growth of Epstein Barr virus B-cell lymphomas. Cancer Res 63(15):4472-4480

27. Kauffman HM, Cherikh WS, Cheng Y, Hanto DW, Kahan BD (2005) Maintenance immunosuppression with target-of-rapamycin inhibitors is associated with a reduced incidence of de novo malignancies. Transplantation 80(7):883-889

28. Nalesnik MA (1997) Clinicopathologic features of posttransplant lymphoproliferative disorders. Ann Transplant 2(4):33-40

29. Dharnidharka VR, Harmon WE (2001) Management of pediatric postrenal transplantation infections. Semin Nephrol 21(5):521-531

30. Caillard S, Dharnidharka V, Agodoa L, Bohen E, Abbott K (2005) Posttransplant lymphoproliferative disorders after renal transplantation in the United States in era of modern immunosuppression. Transplantation 80(9):1233-1243

31. Kremers WK, Devarbhavi HC, Wiesner RH, Krom RA, Macon WR, Habermann TM (2006) Post-transplant lymphoproliferative disorders following liver transplantation: incidence, risk factors and survival. Am J Transplant 6(5 Pt 1):1017-1024

32. Ghobrial IM, Habermann TM, Maurer MJ, Geyer SM, Ristow KM, Larson TS, Walker RC, Ansell SM, Macon WR, Gores GG, Stegall MD, McGregor CG (2005) Prognostic analysis for survival in adult solid organ transplant recipients with post-transplantation lymphoproliferative disorders. J Clin Oncol 23(30):7574-7582

33. Ghobrial IM, Habermann TM, Ristow KM, Ansell SM, Macon W, Geyer SM, McGregor CG (2005) Prognostic factors in patients with post-transplant lymphoproliferative disorders (PTLD) in the rituximab era. Leuk Lymphoma 46(2):191-196

34. Tsai DE, Hardy CL, Tomaszewski JE, Kotloff RM, Oltoff KM, Somer BG, Schuster SJ, Porter DL, Montone KT, Stadtmauer EA (2001) Reduction in immunosuppression as initial therapy for 
posttransplant lymphoproliferative disorder: analysis of prognostic variables and long-term follow-up of 42 adult patients. Transplantation 71(8):1076-1088

35. McCormack L, Hany TI, Hubner M, Petrowsky H, Mullhaupt B, Knuth A, Stenner F, Clavien PA (2006) How useful is PET/CT imaging in the management of post-transplant lymphoproliferative disease after liver transplantation? Am J Transplant 6 (7):1731-1736

36. Dharnidharka VR, Richard GA, Neiberger RE, Fennell RS (2002) Cat scratch disease and acute rejection after pediatric renal transplantation. Pediatr Transplant 6(4):327-331

37. Green M, Michaels MG, Webber SA, Rowe D, Reyes J (1999) The management of Epstein-Barr virus associated post-transplant lymphoproliferative disorders in pediatric solid-organ transplant recipients. Pediatr Transplant 3(4):271-281

38. Oertel SH, Anagnostopoulos I, Bechstein WO, Liehr H, Riess HB (2000) Treatment of posttransplant lymphoproliferative disorder with the anti-CD20 monoclonal antibody rituximab alone in an adult after liver transplantation: a new drug in therapy of patients with posttransplant lymphoproliferative disorder after solid organ transplantation? Transplantation 69(3):430-432

39. Choquet S, Leblond V, Herbrecht R, Socie G, Stoppa AM, Vandenberghe P, Fischer A, Morschhauser F, Salles G, Feremans W, Vilmer E, Peraldi MN, Lang P, Lebranchu Y, Oksenhendler E, Garnier JL, Lamy T, Jaccard A, Ferrant A, Offner F, Hermine O, Moreau A, Fafi-Kremer S, Morand P, Chatenoud L, BerriotVaroqueaux N, Bergougnoux L, Milpied N (2006) Efficacy and safety of rituximab in B-cell post-transplantation lymphoproliferative disorders: results of a prospective multicenter phase 2 study. Blood 107(8):3053-3057

40. Gross TG, Bucuvalas JC, Park JR, Greiner TC, Hinrich SH, Kaufman SS, Langnas AN, McDonald RA, Ryckman FC, Shaw BW, Sudan DL, Lynch JC (2005) Low-dose chemotherapy for Epstein-Barr virus-positive post-transplantation lymphoproliferative disease in children after solid organ transplantation. J Clin Oncol 23 (27):6481-6488

41. Elstrom RL, Andreadis C, Aqui NA, Ahya VN, Bloom RD, Brozena SC, Olthoff KM, Schuster SJ, Nasta SD, Stadtmauer EA, Tsai DE (2006) Treatment of PTLD with rituximab or chemotherapy. Am J Transplant 6(3):569-576

42. Sarwal MM, Vidhun JR, Alexander SR, Satterwhite T, Millan M, Salvatierra O Jr (2003) Continued superior outcomes with modification and lengthened follow-up of a steroid-avoidance pilot with extended daclizumab induction in pediatric renal transplantation. Transplantation 76(9):1331-1339

43. Shapiro R, Ellis D, Tan HP, Moritz ML, Basu A, Vats AN, Khan AS, Gray EA, Zeevi A, McFeaters C, James G, Jo Grosso M, Marcos A, Starzl TE (2006) Antilymphoid antibody preconditioning and tacrolimus monotherapy for pediatric kidney transplantation. J Pediatr 148(6):813-818

44. Qu L, Green M, Webber S, Reyes J, Ellis D, Rowe D (2000) Epstein-Barr virus gene expression in the peripheral blood of transplant recipients with persistent circulating virus loads. J Infect Dis 182(4): 1013-1021

45. Johnson SR, Cherikh WS, Kauffman HM, Pavlakis M, Hanto DW (2006) Retransplantation after post-transplant lymphoproliferative disorders: an OPTN/UNOS database analysis. Am J Transplant 6 (11):2743-2749

\section{Answers}

1) Answer: c Rationale: cyclophosphamide is used as a component of the CHOP protocol of chemotherapy (cyclophosphamide, hydroxydaunorubicin, vincristine, and prednisone) for advanced PTLD, but not as prophylaxis. Reduction of immunosuppression and anti-viral agents can be used as either prevention or treatment strategies.

2) Answer: d Rationale: serial EBV PCR monitoring can be used to detect high viral loads prior to PTLD development and can potentially be used to monitor treatment efficacy, but it is not a treatment intervention itself.

3) Answer: c Rationale: central nervous system involvement has consistently been associated with the worst prognosis across different types of organ transplants. Allograft involvement is associated with a good prognosis in kidney transplants, though the prognosis is not as good when allograft failure is directly life-threatening, as in thoracic organ transplants.

4) Answer: d Rationale: male gender and Caucasian race have been found to be risk factors for PTLD. In general, the higher the burden of immunosuppression, the higher the risk for PTLD. However, MMF has not been associated with higher PTLD risk, though it has been associated with higher risk of CMV and BK virus infection.

5) Answer: a Rationale: EBV has been intimately linked to PTLD by epidemiologic, molecular and immunostaining analyses. CMV may be a co-factor, while urinary tract infection (UTI) and BK virus infection have not been associated with PTLD.

6) Answer: c Rationale: cellular immunity is thought to be more important in the control of proliferating infected B cells through EBV-specific cytotoxic T lymphocytes.

7) Answer: a Rationale: PTLD occurs more commonly within the first year of transplantation in children receiving kidney transplants, when more intense immunosuppression is used and EBV primary infection is more likely in a donor positive/recipient negative mismatch.

8) Answer: b Rationale: EBV viral loads may be elevated in the absence of PTLD and should not replace histologic examination of suspected sites of PTLD involvement. 